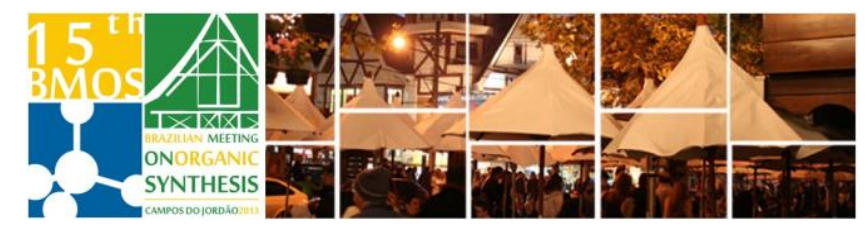

\title{
Efficient synthesis via molecular sieve of 3-(pyrimidin-2yl)- thiazolidinones
}

\author{
Ribeiro, C.S. ${ }^{1}$; Campos Jr, J.C. ${ }^{*}$; Bierhals, M.P. ${ }^{1}$; Freitag, R.A.; Cunico, W. ${ }^{1}$;Siqueira, \\ G.M. ${ }^{1}$ \\ ${ }^{1}$ Laboratório de Química Aplicada a Bioativos - LAQUIABIO, CCQFA, UFPel \\ *coanjunior@gmail.com
}

Keywords: thiazolidinones, molecular sieves, pyrimidine derivatives

\section{INTRODUCTION}

Several methods for the synthesis of thiazolidin-4ones are described in the literature ${ }^{1}$. The most often used involves three components: a primary amine, a carbonyl compound and mercaptoacetic acid using azeotropic distillation with Dean-Stark trap, for the water removal, is the most common approach. Besides, other protocols were developed by using dehydrating agents among these $\mathrm{Na}_{2} \mathrm{SO}_{4}$, molecular sieves, DCC and others, with the purpose to improve the yield of the products. $^{2}$

The aim of this study was explore the application of molecular sieves in compare with Dean-Satrk trap, as dehydrating agents in the synthesis of 3(pyrimidin-2-yl)-thiazolidinones.

\section{RESULTS AND DISCUSSION}

In attempting to work with a less toxic solvents, some reactions with molecular sieve were tested with: ethanol, isopropanol, and tetrahydrofuran, however, toluene showed the best results. Moreover, high temperature $\left(\sim 80^{\circ} \mathrm{C}\right)$ an $\mathrm{BF}_{3}$ addition increased the efficiency of the reactions with molecular sieve, similar that reported by Gouvêa et al. under azeotropic distillation. ${ }^{3}$

The proposed compounds, 4a-k, were obtained in two steps as show in Scheme 1. The progress of reactions was monitored by $G C$ and TLC, and the compounds were confirmed by GC-MS and melting point determination. The novel compounds $4 c, 4 e-$ $\mathbf{g}$ and $4 \mathbf{i}$ were also characterized by ${ }^{1} \mathrm{H}$ and ${ }^{13} \mathrm{C}$ NMR.

The synthesis using molecular sieve showed moderate yields when compared to use of azeotropic distillation Table 1.

Scheme 1.

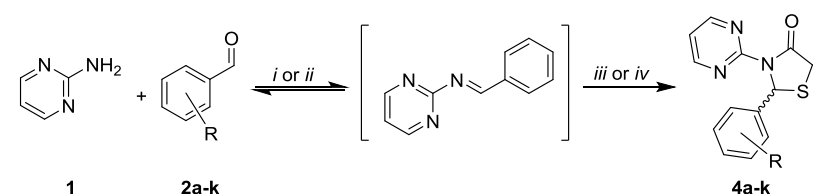

I: toluene, $\mathrm{BF}_{3}: \mathrm{MeOH}$, reflux in Dean-Stark trap, $3 \mathrm{~h}$; ii: toluene, $\mathrm{BF}_{3}: \mathrm{MeOH}$, molecular sieve, $80^{\circ} \mathrm{C}, 3 \mathrm{~h}$; iii: $\mathrm{HSCH}_{2} \mathrm{COOH} 3$, reflux in Dean-Stark trap, $16 \mathrm{~h}$; iv: $\mathrm{HSCH}_{2} \mathrm{COOH} 3$, molecular sieve, $80^{\circ} \mathrm{C}, 16 \mathrm{~h}$.

$15^{\text {th }}$ Brazilian Meeting on Organic Synthesis $-15^{\text {th }}$
Table 1. Yields of compounds 4a-k.

\begin{tabular}{ccccc}
$\begin{array}{c}\text { Produc } \\
\mathrm{t}\end{array}$ & $\mathrm{R}$ & m.p. $\left({ }^{\circ} \mathrm{C}\right)^{\mathrm{a}}$ & $\begin{array}{c}\text { Mol. S. } \\
\text { Yield } \\
(\%)^{\mathrm{b}}\end{array}$ & $\begin{array}{c}\text { Conv. } \\
\text { Yield } \\
(\%)^{\mathrm{c}}\end{array}$ \\
\hline $\mathbf{4 a}$ & $4-\mathrm{CH}_{3}$ & $147-150$ & 35 & 53 \\
$\mathbf{4 b}$ & $2-\mathrm{Cl}$ & $172-175$ & 54 & 77 \\
$\mathbf{4 c}$ & $3-\mathrm{F}$ & $166-168$ & 30 & 45 \\
$\mathbf{4 d}$ & $4-\mathrm{F}$ & $143-146$ & 49 & 73 \\
$\mathbf{4 e}$ & $3-\mathrm{OMe}$ & $144-147$ & 37 & 60 \\
$\mathbf{4 f}$ & $2-\mathrm{NO}_{2}$ & $174-177$ & 56 & 98 \\
$\mathbf{4 g}$ & $3-\mathrm{NO}_{2}$ & $175-178$ & 52 & 76 \\
$\mathbf{4 h}$ & $2,4-\mathrm{Cl}$ & $178-180$ & 46 & 73 \\
$\mathbf{4 i}$ & $2,3-\mathrm{OMe}$ & $131-135$ & 52 & 82 \\
$\mathbf{4 j}$ & $3,4-\mathrm{OMe}$ & $102-105$ & 38 & 63 \\
$\mathbf{4 k}$ & $2-\mathrm{Cl}, 6-\mathrm{F}$ & $132-135$ & 33 & 51 \\
\hline
\end{tabular}

${ }^{a}$ Melting point are uncorrected. ${ }^{b}$ Yields of pure compounds Molecular sieve. ${ }^{c}$ Yields of pure compounds - Conventional.

\section{CONCLUSION}

We report the efficient synthesis of eleven compounds of 2-(aryl)-3-(pyrimidin-2-yl)-1,3thiazolidin-4-one using a molecular sieve that furnishes the desired products in a lower energy $\left(\sim 80^{\circ} \mathrm{C}\right)$. Moreover, the procedure showed advantages like operational simplicity, moderate yields and overall lower cost.

\section{ACKNOWLEDGEMENTS}

The authors thank to CAPES, CNPq, FAPERGS and UFPel.

\section{REFERENCES}

1. Jain, A. K.; Vaidya, A.; Ravichandran, V.; Kashaw, S. K.; Agrawal, R. K., Bioorganic \& Medicinal Chemistry 2012, 20 (11), 3378-3395.

2. Prasad, D.; Nath, M., J. Heterocycl. Chem. 2012, 49 (3), 628-633.

3. Gouvea, D. P.; Bareno, V. D. O.; Bosenbecker, J.; Drawanz, B. B.; Neuenfeldt, P. D.; Siqueira, G. M.; Cunico, W., Ultrason. Sonochem. 2012, 19 (6), 1127-1131.

Campos, J. C.; Gouvêa, D. P.; Ribeiro, C. d. S. et al, $J$ Biochem. Mol. Tox. 2013, 27 (9), 445-450. 